\title{
Urban heat island analysis for Bangkok: multi-scale temporal variation, associated factors, directional dependence, and cool island condition
}

\author{
Jirawan Kamma $^{\mathrm{a}, \mathrm{b}}$, Kasemsan Manomaiphiboon ${ }^{\mathrm{a}, \mathrm{b}, *}$, Nishit Aman ${ }^{\mathrm{a}, \mathrm{b}}$, Tara Thongkamdee ${ }^{\mathrm{c}}$, \\ Surawut Chuangchote ${ }^{\mathrm{d}}$, Sebastien Bonnet ${ }^{\mathrm{a}, \mathrm{b}}$ \\ a The Joint Graduate School of Energy and Environment, King Mongkut's University of Technology \\ Thonburi, Thailand \\ b Center of Excellence on Energy Technology and Environment, Ministry of Higher Education, Science, \\ Research and Innovation, Thailand \\ c Thai Meteorological Department, Ministry of Digital Economy and Society, Thailand \\ ${ }^{d}$ Department of Tool and Materials Engineering, Faculty of Engineering, King Mongkut's University of \\ Technology Thonburi, Thailand
}

*Corresponding author, e-mail: kasemsan.jgsee@gmail.com

Received 26 Feb 2019

Accepted $15 \mathrm{Feb} 2020$

\begin{abstract}
This study analyzed urban heat island characteristics in Bangkok, observed during a period of 10 years (2006-2015) with emphasis on the dry season when the urban heat island is intensified in both daytime and nighttime as compared to the wet season. December-January was found to be the months of peak urban heat island intensity (UHI) in terms of average. The intensity is relatively large at night due to the faster cooling rate during the early evening at the rural site whose thermal admittance of land surface is lower than the urban site. UHII is slightly larger during the weekdays than the weekend, suggesting certain degree of influence of anthropogenic heat emitted in the urban area. UHII is negatively correlated with most of rain, cloud, relative humidity, and wind speed variables. The assessment of polar plots shows UHII dependence on wind direction. The statistical regression models relating UHII to selected meteorological variables are capable of explaining the variability of the original data by $82 \%$ for daytime UHII and $66 \%$ for nighttime. Southwesterly wind direction and persistence were found to be important in modulating UHII, and both appear in the final regression models. The presence of dry-season cool island events was also investigated, and it was found that they are generally induced by the high intensity of urban-alone/urban-rural rain, cloud, relative humidity, or urban wind speed (or combined). Overall, the findings from the study provide enhanced perspectives, which can support urban policy and planning related to weather for the study area.
\end{abstract}

KEYWORDS: urbanization, temperature, urban climate, cool island, Thailand

\section{INTRODUCTION}

Urbanization involves land cover modification with expanded built areas (i.e., urban sprawl), increased population accompanied by human activities, and more energy consumption. In a highly urbanized area or city, the presence of developed areas, tall buildings, and dense roadways with surface concrete/asphalt paving often come with reduced green areas, setting a topographical contrast between the urban area and its nearby rural area. Anthropogenic heat emissions due mostly to energy usage (fuel combustion and electricity) may be relatively large in urban areas $[1,2]$. These factors can induce changes in climatic conditions between the urban and rural areas. Urban heat island (UHI) has been known as a phenomenon where urban temperature is higher than rural temperature $[1,3]$. The UHI intensity (UHII) is defined as the difference between urban air temperature $\left(T_{\mathrm{u}}\right)$ and rural air temperature $\left(T_{\mathrm{r}}\right)$ i.e., $\Delta T_{\mathrm{u}-\mathrm{r}}=T_{\mathrm{u}}-T_{\mathrm{r}}$. Air temperature is generally referenced at a near-surface level within an urban canopy. Nevertheless, land surface temperature and air temperature aloft can also be used to define UHII [3-5]. In other words, the UHI definition considered here is for urban canopy layer, which generally represents microscale conditions influenced by buildings, vegetation, and intervening spaces [3]. Since near-surface air temperature is simply utilized in the UHI calculation, data recorded 

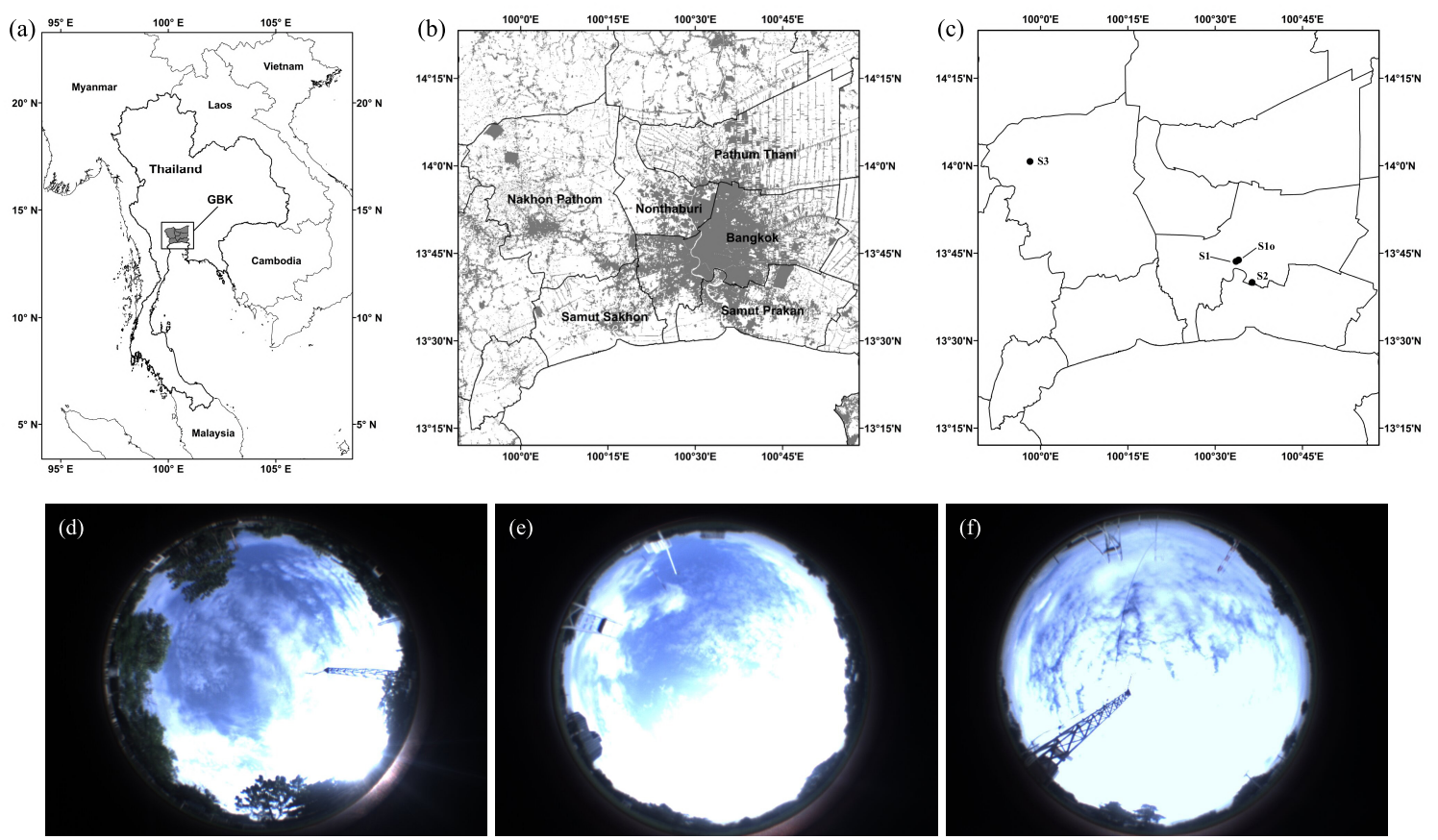

Fig. 1 (a-c) Greater Bangkok (GBK) (including Bangkok and five neighboring provinces). Grey shading denotes urbanized or built-up areas. (d-f) Sky-view photos (taken in December 2016) at stations S1 (urban in Bangkok), S2 (urban in Bangkok), and S3 (rural in Nakhon Pathom).

at standard weather stations can be readily accessed and used, and its characteristics are inter-related to surface energy balance, near-surface turbulence, and anthropogenic heat. However, the roles of synoptic winds and long-distance heat transport are unable to be well accounted for by this type of UHI.

Urban temperature tends to be higher than rural temperature because of the physical properties of urban surface, especially lower albedo and larger thermal admittance [6]. Thus, the urban surface tends to absorb more solar radiation and store more heat during the daytime and release the stored heat back to the atmosphere in the nighttime while the rural surface warms and cools relatively faster. These cause UHI to be most intensified at night. During calm wind conditions, a shallow convective layer may develop above an urban core and then cause air to flow from its outer areas towards and converge at the urban core, which lessens the ventilation of air pollutants. Moreover, UHI is known to intensify during an extended hot period or a heat wave, making urban population in large cities more vulnerable to heat or thermal pollution [7]. Temperature, health problems, and mortality have been found to be associated in urban studies [8]. From a macroscopic viewpoint, UHI correlates with population size and urbanization extent $[9,10]$. In the summer, relatively warm temperature leads to a higher power demand for air conditioning and thus larger heat emitted to the atmosphere. Therefore, the issue of UHI has direct implications for urban sustainability in environment, energy, and health policy and planning. In fact, UHI is a central subject in the field of urban climates, which has been widely studied [11-13].

Bangkok is the capital city of Thailand (Fig. 1) and the largest province in terms of population and urbanization. It is a strategic, economic hub that accounts for as much as $46 \%$ of the total GDP (as of the year 2015), according to the Office of the National Economic and Social Development Board. In fact, its continuous growth is not limited to Bangkok but extends to its neighboring areas [14], combined as a large urban agglomeration called the Greater Bangkok (GBK) (Fig. 1b). Administratively, GBK consists of six provinces: Bangkok, Samut Prakan, Samut Sakhon, Nonthaburi, Nakhon Pathom, and Pathum Thani. Given the significance of Bangkok, its climatic conditions are inevitably an important issue for the public. A number of UHI-related studies have been conducted for the province but varied greatly in type of UHI, objec- 
tive, method, and analytical intensiveness. As a pioneered UHI investigation, Boonjawat et al [15] employed air temperature data measured in 1998 from a private network of automated stations to assess UHI in Bangkok and supplemented discussion using some landscape and satellite images. Jongtanom et al [16] reported preliminary results on the average diurnal and monthly variations of UHII in three selected major provinces (including Bangkok). Pakarnseree et al [17] related seasonal change in air temperature in terms of cooling rate for various subdivisions over the city to their physical landscape properties (street/park/water/building spaces and building-floor area) in four separate years starting from 2000. Satellite-based land surface temperature data can be utilized to determine the extent of urban expansion and surface urban heat island (SUHI), potentially useful for city planning and developing UHI mitigation strategies. Such satellitebased data were applied to Bangkok by some studies $[5,18]$. To our knowledge, no studies have yet been found for comprehensive characterization of $\mathrm{UHI}$ and its meteorological association for Bangkok, and none has addressed cool island conditions in the province. The cool island is the phenomenon opposite of UHI i.e., rural temperature being larger than urban temperature (i.e., negative UHII). In the literature, the cool island has not been much addressed or often briefly mentioned $[19,20]$. Thus, it is of current interest to examine the cool island in more details. Many of the above-mentioned UHI studies for Bangkok employed observational data with a limited period and did not provide attention to the selection of reference urban and rural sites, which may result in less reliability in their reported findings. For UHI studies, it is crucial to properly select the reference urban and rural sites $[18,21]$. Our effort here aims to fill such gaps and, importantly, improve the existing understanding of UHI for Bangkok, which can be useful information to support environmental policy and planning towards the goal of urban sustainability in the future.

\section{MATERIALS AND METHODS}

\section{Study area}

Bangkok ( $13^{\circ} 45^{\prime}$ lat. and $100^{\circ} 28^{\prime}$ lon.) is geographically situated in the central plain of Thailand, which is the alluvial basin of the Chao Phraya River. It is adjacent to the Gulf of Thailand to the south, with a distance of $25 \mathrm{~km}$ from the city center and the coast. The terrain elevation is generally flat and on average $1.5 \mathrm{~m} \mathrm{msl}$ (above mean sea level).
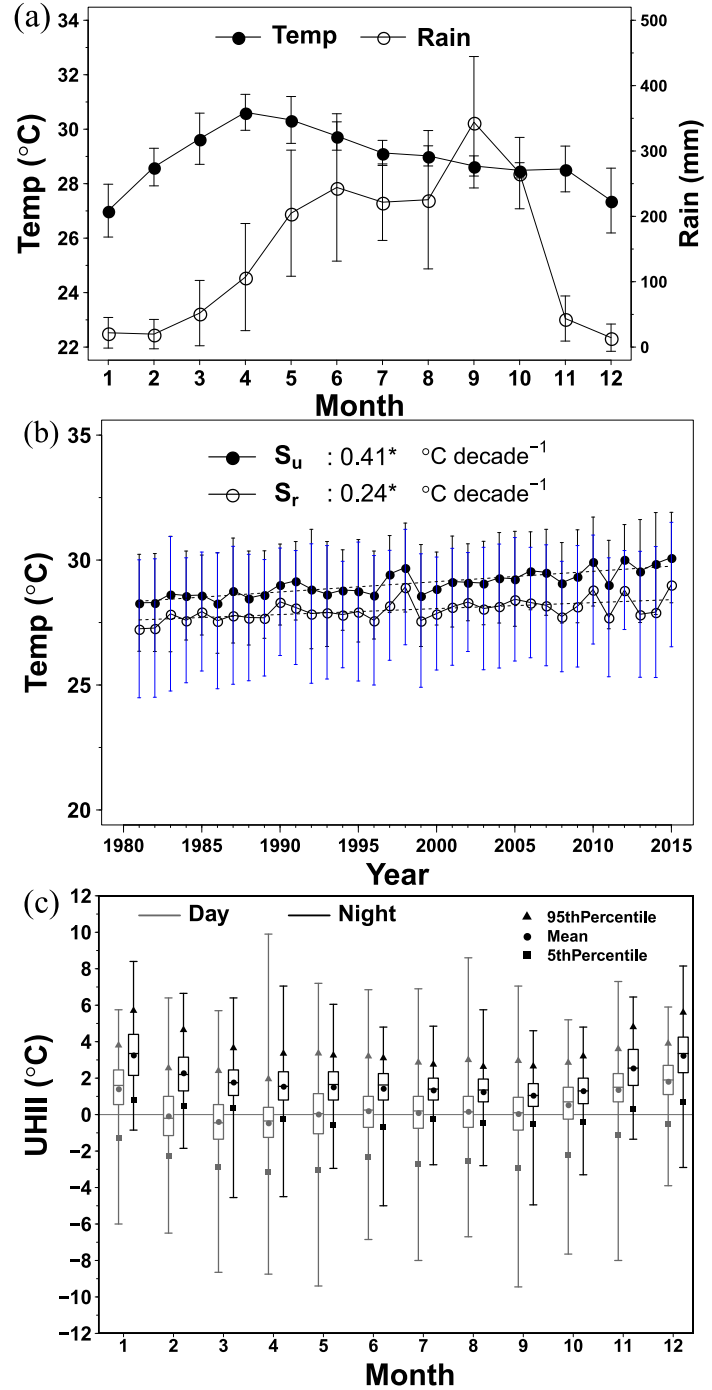

Fig. 2 (a) Annual cycle of climatological temperature and rain at the urban site in 2006-2015, (b) trends in mean temperature, and (c) annual cycle of daytime and nighttime UHII in 2006-2015, showing the box-whisker plots. In (a,b), vertical bar is mean \pm SD. In (c), the top and bottom horizontal bars mark the maximum and minimum, respectively. The bottom, middle, and top horizontal lines of each rectangular box denote the 1st, 2nd (or median), and 3rd quartiles, respectively. Each circle denotes the mean or average.

Bangkok is administratively divided into 50 districts and covers a total area of $1568.7 \mathrm{~km}^{2}$. According to the National Statistical Office of Thailand, it has a total registered population of 5.5 million and a large latent (non-registered) population which is estimated to be about $40 \%$ more. As mentioned previously, the Greater Bangkok (GBK) agglomer- 
ation comprises Bangkok and its five surrounding provinces with a total area of $7762 \mathrm{~km}^{2}$ and a population of over 10 million. In the southern part of GBK (especially, Samut Prakan and Samut Sakon), many industrial factories are present. The general climate of GBK is like most part of Upper Thailand, which is influenced by the northeast and southwest monsoons [22,23]. The former monsoon prevails during Nov-Feb and brings cool dry air masses from mainland China, corresponding to the winter. In Mar-Apr, the northeast monsoon becomes weakened, and air temperature begins to increase, resulting in the warmest period of the year (i.e., the summer). Given no strong influences from the two monsoons during these two months, southerly winds from the Gulf of Thailand synoptically prevail. The southwest monsoon approximately starts in May and lasts until October, bringing abundant moisture from Indian Ocean and the Gulf of Thailand along its passage and thus substantial rain. According to these distinct seasonal features (Fig. 2a), the dry season (Nov-Apr) and the wet season (May-Oct) were considered in our UHI assessment. The wet season contributes over $80 \%$ of total annual rainfall, based on the obtained rainfall data. Because the dry season crosses over two calendar years, the dry season of a particular year is formed by Nov-Dec of the previous year and Jan-Apr of that year.

\section{Data}

Several weather stations of the Thai Meteorological Department (TMD) located in the GBK were initially considered. However, their monitoring differs in temporal coverage (e.g., 8-35 years), hour-of-day span (e.g., daytime only as opposed to both daytime and nighttime), and sampling frequency (e.g., hourly, three-hourly, and daily), thus posing difficulty in choosing a pair of reference urban and rural sites. Initially, three-hourly data (including temperature, rain, cloud cover, relative humidity, and wind speed/direction) from eight stations were obtained and also checked for time coverage, implausible values and data adequacy for every variable (here, temperature, rain, cloud cover, relative humidity, and wind). The amount of non-missing (i.e., valid) values was found to be at least $85 \%$. Given the long-term data used in the study, we performed additional data checking as follows: (a) valid values within the ranges of $0-50^{\circ} \mathrm{C}$ for temperature and $0-100 \%$ for relative humidity, and (b) non-outliers to be within the range of mean \pm 5 times standard deviation. It is noted that temperature and humidity were measured at $1.5 \mathrm{~m}$ agl (above ground level), and wind measurement is at $10 \mathrm{~m}$ agl.

In selecting the reference sites for the analysis, they should in principle not be close to a large water body or river. In the study, we conducted a field visit to each weather station (six in total) located within the study area to examine its actual environment. We computed total built-up amount corresponding to each station using a $10-\mathrm{km}$ radius using a land cover database of the Land Development Department (LDD) for the year 2009 (Fig. 1). It is noted that no size or radius has been universally proposed for use to classify the type of station in urban heat island studies. For example, Yang et al [24] tried a set of radii (ranging 1-20 km) and chose $7 \mathrm{~km}$ as the threshold. According to the above procedure, we found S1 and S2 (separated by $8 \mathrm{~km}$ ) in Bangkok as the urban sites and S3 in Nakhon Pathom as the rural site representatively. Both S1 and S2 share a similar background, which is a business area with buildings, houses, parks, and streets. Their total built-up areas are about $80 \%$ (Fig. $1 \mathrm{~d}$ and e). Fisheye photographs were also taken during the station visits using an all-sky camera set at a height of $1 \mathrm{~m}$ agl to estimate sky-view factor (SVF), defined as the ratio of the area of sky portion to that of the hemisphere. The SVF values at both S1 and S2 are $>60 \%$ (here, $63 \%$ and $80 \%$, respectively) (Fig. 1d and e), indicating no severe obstruction or blocking of air ventilation and radiation. Because the data at both stations tend to be well correlated (e.g., $>0.9$ for three-hourly temperature and relative humidity), average values from the two stations were then used, and the middle location between both stations was designated as the official reference urban site $\left(S_{\mathrm{u}}\right)$. Station S3 is the reference rural site $\left(S_{\mathrm{r}}\right)$. Its background is an open green area with a total built-up area of $22 \%$ and a SVF of $82 \%$ (Fig. 1f). The distance between $S_{\mathrm{u}}$ and $S_{\mathrm{r}}$ is about $70 \mathrm{~km}$. We further roughly estimated total builtup amount based on an alternative dataset (GoogleEarth satellite images) but at a closer proximity (2-km radius) for the year 2010 and found 93\% at S1, 85\% at S2, and $25 \%$ at S3 as a result (not shown), which is also consistent with those based on the LDD data. Arguably, the fair amount of total built-up area at S3 may theoretically not classify it as an ideal rural site. In the current context, it is nonetheless used as our best rural-site candidate. In view of local climate zone classification [6], given the available information, $S_{\mathrm{u}}$ appears to match local climate zone (LCZ) Type 2 (compact midrise) while $S_{\mathrm{r}}$ approximately matches LCZ Type 9 (sparsely built). 
The temporal coverage of the three-hourly data at $S_{\mathrm{u}}$ and $S_{\mathrm{r}}$ is from 2006-2015 (10 years). The amount of non-missing (i.e., valid) values was found to be at least $85 \%$ for every variable (here, temperature, rain, cloud cover, relative humidity, and wind) at each station. Given the three-hourly data, 10-19 LT (local time) were used as the daytime hours while the nighttime hours consisted of 22 LT (of current day) and 01-07 LT (of the next day). In addition to the three-hourly data, long-term (35 years, 1981-2015) daily maximum and minimum temperature data were obtained and averaged as daily mean temperature. Both stations commonly have a significantly positive trend of temperature $\left(0.41^{\circ} \mathrm{C} /\right.$ decade at $S_{\mathrm{u}}$ and $0.24^{\circ} \mathrm{C} /$ decade at $S_{\mathrm{r}}$, Fig. $2 \mathrm{~b}$ ), which is attributed to the combined result of urbanization and climate change (i.e., global warming). Previous studies [22,25] reported the warming trends of temperature across Thailand over recent decades as a result of climate change. Given that both sites are located in GBK, the larger trend found at $S_{\mathrm{u}}$ is thus due to the effect of relatively high urbanization.

\section{RESULTS AND DISCUSSION}

\section{Monthly and diurnal variation and weekday- weekend difference}

The monthly variation (or annual cycle) of UHII shows seasonality for both daytime and nighttime UHII (Fig. 2c), which is larger (smaller) in the dry (wet) season in terms of mean UHII. The urban heat island is most intensified during Dec-Jan. The maximum UHII based on the three-hourly data is as much as about $10^{\circ} \mathrm{C}$ in Apr. According to this, dry-season is the main emphasis of this study. It is noted that the wet season has more precipitation, causing complexity given that soil and surface moisture is well present and can be persistent due to its long memory [31] and then impacting climatic conditions, including temperature, through landsurface processes. The UHI analysis for the wet season may not be as straightforward and requires a careful treatment, which is beyond the current scope of this study. Nighttime UHII is generally stronger than the daytime counterpart as reported in $[10,16,19,27,28]$. The cool island (i.e., negative urban heat island) is also present every month. UHII varies with hour of day, as seen in Fig. 3a for the dry season. The intensity is relatively high, starting from 22 LT till 7 LT. Mean UHII in Singapore City peaks at 21 LT (i.e., a couple of hours after sunset) [19]. In general, both urban and rural surfaces
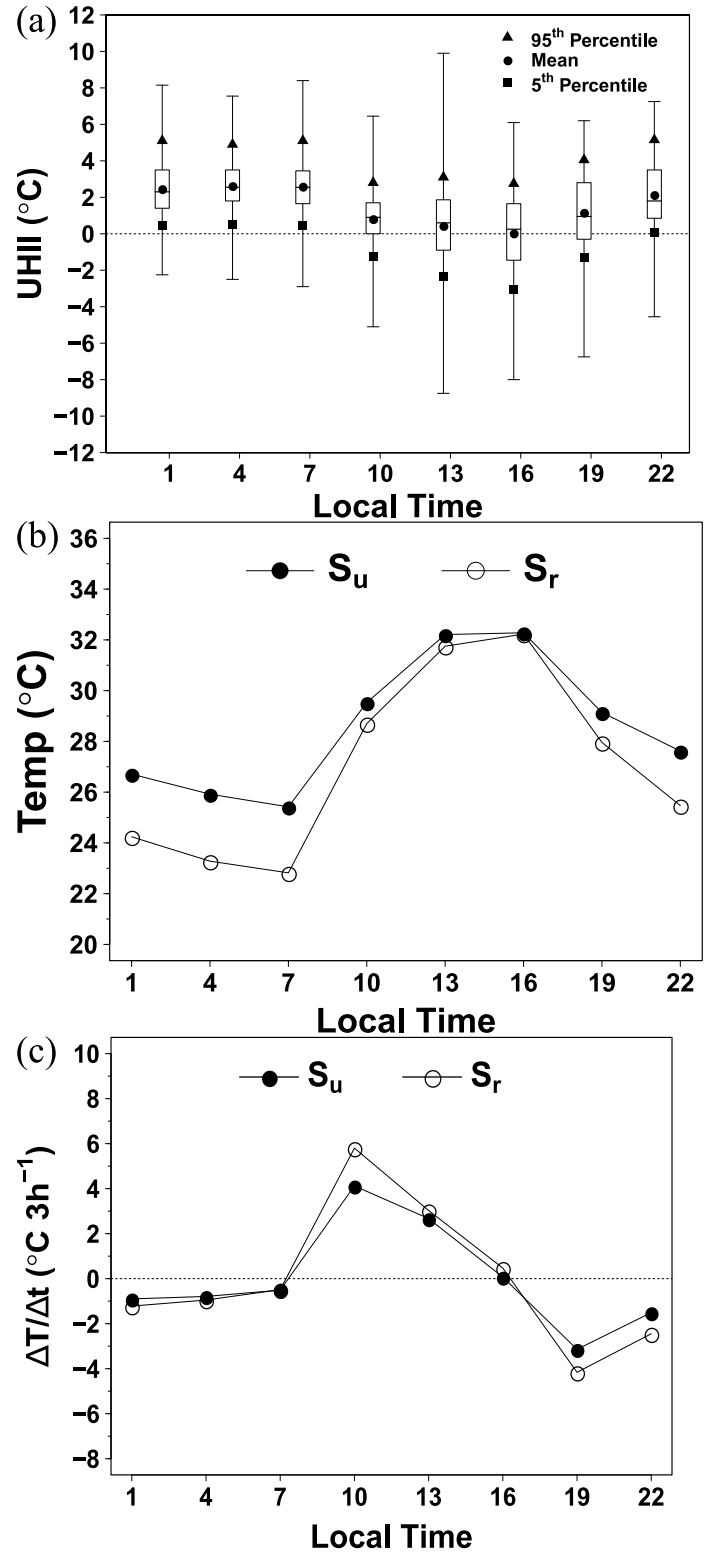

Fig. 3 (a) Diurnal cycle of UHII, (b) diurnal cycle of temperature at the urban $\left(S_{\mathrm{u}}\right)$ and rural $\left(S_{\mathrm{r}}\right)$ sites, (c) same as (b) but for heating rate. All figures are of the dry season in 2006-2015.

become warm after sunrise and peak in the mid-late afternoon (Fig. 3b). As seen, the rural surface (or air) typically gets warm faster during the day and cools faster in the evening. To explain this, surfaceair heating rate at each of the urban and rural sites is examined (Fig. 3c), which is defined as follows:

$$
\left(\frac{\Delta T}{\Delta t}\right)_{n}=\frac{T_{n}-T_{n-3}}{t_{n}-t_{n-3}}
$$



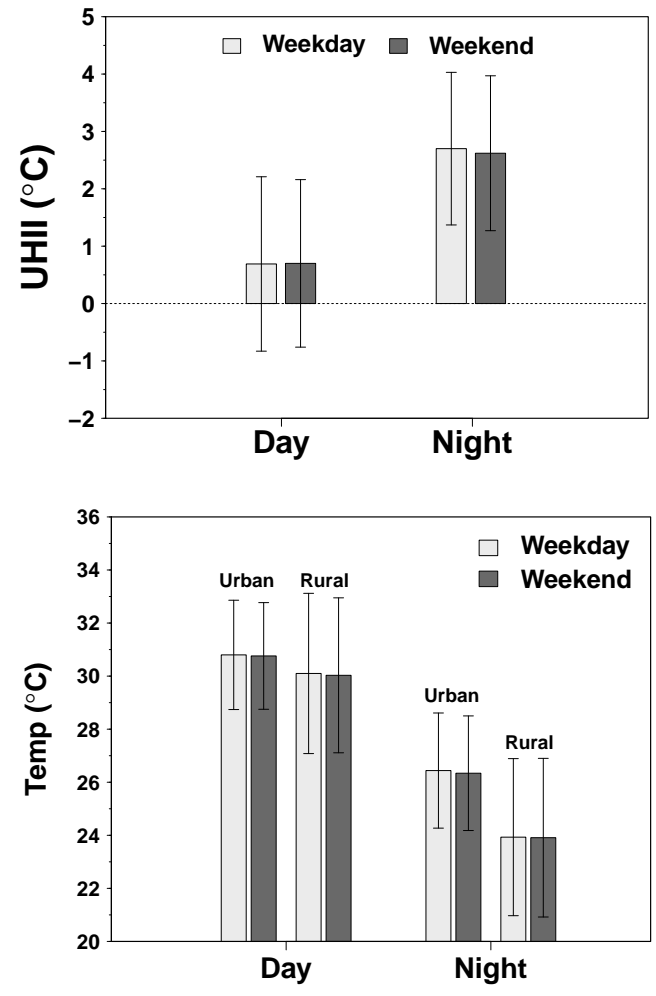

Fig. 4 UHII and temperature over the weekday (Mon-Fri) and weekend (Sat-Sun) periods. All figures are of the dry season in 2006-2015.

where the left-hand side term is the heating rate at current hour $t_{n}, T_{n}$ is the temperature at $t_{n}$, and $T_{n-3}$ is the temperature at three hours earlier (given the three-hourly data). At both sites, the warming rate (temperature at 10 LT minus that at $7 \mathrm{LT})$ peaks at $10 \mathrm{LT}\left(5.8^{\circ} \mathrm{C} / 3 \mathrm{~h}\right)$ while the maximal cooling rate $\left(-4.5^{\circ} \mathrm{C} / 3 \mathrm{~h}\right)$ is at $19 \mathrm{LT}$, but with the larger magnitudes at the rural site. This can be explained by the concept of thermal admittance. From the previous sub-section (Data), the urban and rural sites are approximated to LCZ types 2 and 9, respectively, which have the corresponding values of thermal admittance of 1200-2200 and 1000$1800 \mathrm{Jm}^{-2} \mathrm{~s}^{-0.5} \mathrm{~K}^{-1}$, respectively (as the suggested values given in Stewart and Oke [6]). Thermal admittance is a property of a surface or material to absorb/release and store heat. The smaller values at the rural site correspond to shorter time (i.e., faster) of the rural surface to respond to and store absorbed solar radiation as heat, which is due mainly to the presence of more open areas with less buildings. Comparing with the Singapore City study using hourly data [19], the maximal cooling rate at most of the urban and rural sites was found at 18 LT.

Whether the urban heat island is dependent on anthropogenic (human-generated) heat is of additional interest because urban areas typically consume considerable energy, which eventually dissipates into heat. Anthropogenic heat sources in an urban area include transportation, cooling and heating buildings, manufacturing and lighting $[1,2,29]$. In context of surface energy balance, such heat may add to sensitive heat, raising surface air temperature. Here, UHII and temperature over the weekday (i.e., working days) and weekend periods are compared. Mon-Fri were assigned as weekdays, and Sat-Sun were assigned as weekend. It is expected that energy usage or heat emission becomes larger during the weekdays at both urban and rural sites, causing weekday temperature to be higher than the weekend for all cases (Fig. 4b). However, for urban heat island, only nighttime UHII shows a contrast of $0.1^{\circ} \mathrm{C}$ (significant at a 0.1 level) between the two periods (Fig. 4a). This is attributed partly to that, in the nighttime, the urban weekend has a more apparent decrease in human activities than the rural weekend. Thus, it is possible to state that both UHII and temperature are dependent on anthropogenic heat but to a small degree whereas land cover is the major factor influencing UHII for the study area. It is noted that the non-parametric Wilcoxon rank sum test was employed to test the statistical significance of difference in the means of two samples.

\section{Meteorological factors and directional dependence}

UHII is known to be influenced by other meteorological variables e.g, rain (R), cloud cover (CC), and relative humidity (RH). The first two variables are known to be associated with the surface energy balance, in which they modulate solar radiation and partitioning heat from the surface to the atmosphere into sensible heat and latent [30]. Relative humidity is a measure of available moisture in the air relative to the saturated condition, which is temperaturedependent following the Clausius-Clapeyron relationship by which relative humidity decreases with increased temperature. In general, relative humidity is also associated with rain and cloud in the same direction. Besides urban weather conditions at the urban site, it is possible to include the urban-rural difference of a meteorological variable since UHII may be influenced by rural weather conditions as well. Liu et al [31] found that urbanization tends to decrease humidity in the Beijing area, leading to urban-rural humidity contrast. For wind, large 
Table 1 Correlation between dry-season daytime and nighttime UHII and meteorological variables and the MLR results.

(a) Correlation

\begin{tabular}{lrr}
\hline Variable & \multicolumn{1}{c}{ UHII $_{\text {day }}$} & UHII $_{\text {night }}$ \\
\hline $\mathrm{R}_{\mathrm{u}}(\mathrm{mm} / 3 \mathrm{~h})$ & $-0.24(\mathrm{~N}=1748)$ & $-0.32(\mathrm{~N}=1750)$ \\
$\Delta \mathrm{R}_{\mathrm{u}-\mathrm{r}}(\mathrm{mm} / 3 \mathrm{~h})$ & $-0.28(\mathrm{~N}=1748)$ & $-0.21(\mathrm{~N}=1750)$ \\
$\mathrm{CC}_{\mathrm{u}}$ (deca, in tenth) & $-0.22(\mathrm{~N}=1750)$ & $-0.42(\mathrm{~N}=1750)$ \\
$\Delta \mathrm{CC}_{\mathrm{u}-\mathrm{r}}$ (deca, in tenth) & $-0.14(\mathrm{~N}=1750)$ & $0.16(\mathrm{~N}=1750)$ \\
$\mathrm{RH}_{\mathrm{u}}(\%)$ & $-0.66(\mathrm{~N}=1750)$ & $-0.46(\mathrm{~N}=1750)$ \\
$\Delta \mathrm{RH}_{\mathrm{u}-\mathrm{r}}(\%)$ & $-0.87(\mathrm{~N}=1750)$ & $-0.65(\mathrm{~N}=1750)$ \\
$\mathrm{WS}_{\mathrm{u}}(\mathrm{m} / \mathrm{s})$ & $0.00(\mathrm{~N}=1742)$ & $-0.09(\mathrm{~N}=1419)$ \\
\hline \hline
\end{tabular}

\begin{tabular}{lc}
\hline \hline (b) MLR & $R^{2}$ \\
\hline $\mathrm{UHII}_{\mathrm{day}}\left({ }^{\circ} \mathrm{C}\right)=0.384-0.024 \Delta \mathrm{R}_{\mathrm{u}-\mathrm{r}}-0.108 \Delta \mathrm{RH}_{\mathrm{u}-\mathrm{r}}-0.225 \mathrm{WD}_{\mathrm{u}}(\mathrm{SW})+0.366 \mathrm{PER}$ & 0.83 \\
Coefficient (standard error, $p$-value): & \\
Intercept $(0.039,<0.01), \Delta \mathrm{R}_{\mathrm{u}-\mathrm{r}}(0.003,<0.01), \Delta \mathrm{RH}_{\mathrm{u}-\mathrm{r}}(0.003,<0.01), \mathrm{WD}_{\mathrm{u}}(\mathrm{SW})(0.042,<0.01),(\mathrm{N}=1727)$ \\
$\mathrm{PER}(0.013,<0.01)$ & 0.65 \\
$\mathrm{UHII}_{\text {night }}\left({ }^{\circ} \mathrm{C}\right)=1.234-0.101 \Delta \mathrm{RH}_{\mathrm{u}-\mathrm{r}}-0.109 \mathrm{CC}_{\mathrm{u}}-0.120 \mathrm{WS}_{\mathrm{u}}+0.323 \mathrm{WD}_{\mathrm{u}}(\mathrm{SW})+0.353$ PER & \\
Coefficient $($ standard error, $p$-value $):$ & $(\mathrm{N}=1338)$ \\
Intercept $(0.085,<0.01), \Delta \mathrm{RH}_{\mathrm{u}-\mathrm{r}}(0.003,<0.01), \mathrm{CC}_{\mathrm{u}}(0.009,<0.01), \mathrm{WS}_{\mathrm{u}}(0.041,<0.01)$, & \\
$\mathrm{WD}_{\mathrm{u}}(\mathrm{SW})(0.060,<0.01), \mathrm{PER}(0.019,<0.01)$ &
\end{tabular}

$\mathrm{N}$ is the number of pairs or records used in calculation. All correlation results are statistically significant at a 0.05 level. $\mathrm{WD}_{\mathrm{u}}(\cdot)$ is the vector-average urban wind direction whose value is 0 and $1 . \mathrm{WD}_{\mathrm{u}}(\mathrm{SW})$ corresponds the southwesterly wind, represented by the third quadrant as seen in the polar plots (Fig. 5a). PER $\left({ }^{\circ} \mathrm{C}\right)$ is the persistence of UHI condition.
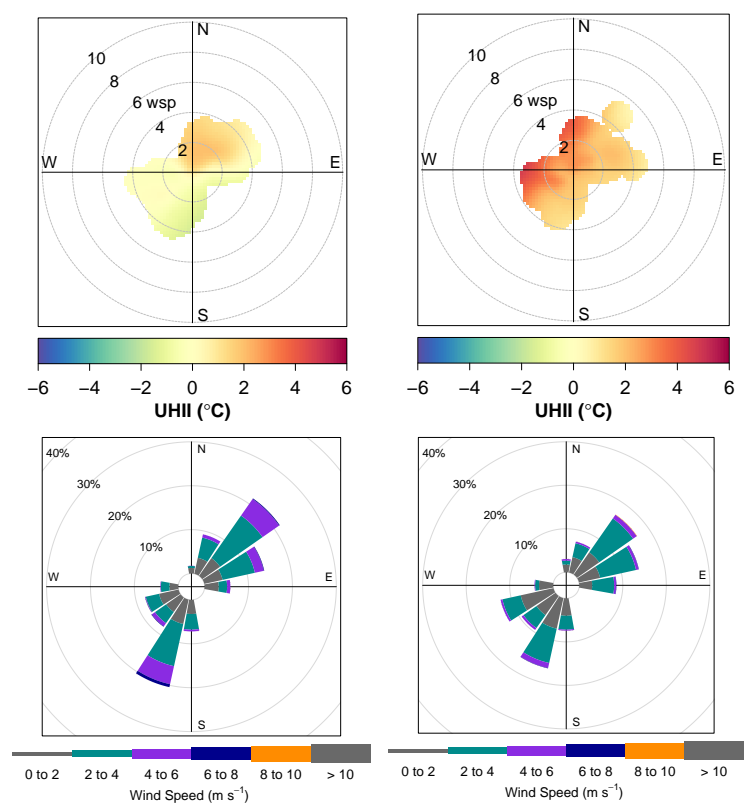

Fig. 5 Polar plots of UHII and wind rose diagrams based on urban wind of the dry season in 2006-2015.

wind speed (WS) can advect heat out of a city and enhance vertical heat mixing, reducing UHII [27]. But wind inside the city can be considerably slowed down by relatively large surface roughness due to the presence of tall or sizable built structures, which is the case of the urbanized areas in Bangkok [32]. Thus, urban wind is essentially an important variable.

Here, correlation analysis was performed to examine the general association of UHII in the dry season and rain (R), cloud cover (CC), and relative humidity $(\mathrm{RH})$ at the urban site as well as their urban-rural differences, and urban wind speed (Table 1), denoted by $\mathrm{R}_{\mathrm{u}}, \Delta \mathrm{R}_{\mathrm{u}-\mathrm{r}}, \mathrm{CC}_{\mathrm{u}}, \Delta \mathrm{CC}_{\mathrm{u}-\mathrm{r}}, \mathrm{RH}_{\mathrm{u}}$, $\Delta \mathrm{RH}_{\mathrm{u}-\mathrm{r}}$, and $\mathrm{WS}_{\mathrm{u}}$. It was found that UHII (both daytime and nighttime) are significantly negatively correlated with all variables for most of the cases (12 out of 14). For $R_{u}$ and $\Delta R_{u-r}$, correlation ranges from -0.32 to -0.21 . Rain brings more moisture to the surface, and then the surface gives out more latent heat and less sensible heat to the air, then reducing temperature. For $\mathrm{CC}_{\mathrm{u}}$, correlation is negative $(-0.22)$ for daytime. During the day, clouds reflect shortwave radiation back into atmosphere, causing less solar radiation at the surface to be available to sensible heat. On the other hand, during the night, longwave radiation emitted from the surface can be trapped by clouds and radiated back downward to surface, warming the surface air. Instead, negative 
correlation is seen for nighttime $(-0.42)$, which is perhaps caused by the net effect of both urban and rural clouds. However, correlation with $\triangle \mathrm{CC}_{\mathrm{u}-\mathrm{r}}$ becomes in line with the above physical explanation i.e., negative $(-0.14)$ for daytime and positive (0.16) for nighttime. Correlation with both $\mathrm{RH}_{\mathrm{u}}$ and $\Delta \mathrm{RH}_{\mathrm{u}-\mathrm{r}}$ is negatively strong $(>0.5)$, which may be explained by the combined effect of the ClausiusClaperon relationship and the association among humidity, cloud, and rain (i.e., more humidity tends to give more clouds/rain, and vice versa). By checking correlation for any pair of $\mathrm{R}_{\mathrm{u}}, \mathrm{CC}_{\mathrm{u}}$, and $\mathrm{RH}_{\mathrm{u}}$, it is positive, ranging from $0.2-0.6$ (not shown). For WS $_{u}$, no correlation with UHII is observed in the daytime; nighttime correlation is negatively small $(-0.09)$ but still significant. It is noted that $\mathrm{WS}_{\mathrm{u}}$ was computed as the speed of the vector-average wind over all daytime/nighttime hours.

The directional dependence of UHII for the dry season in both daytime and nighttime was investigated using polar plots [33] (Fig. 5). The corresponding wind rose diagrams are also given. It is noted that a polar plot displays a quantity of interest (here, UHII) as a function of wind speed and direction while a wind rose diagram displays the frequency of wind occurrence by wind sector and speed interval. Both polar plots and wind rose diagram use the standard definition of wind direction i.e., wind blowing towards the center and the angle is clockwise from the north axis. The wind rose diagrams for daytime and nighttime are similar, showing two prevailing winds (northeasterlyeasterly and southerly-southwesterly). The former is due mainly to the northeast monsoon, but the latter is the combination of sea breeze and the summer Gulf wind. Sea breeze is generally well present along the coastal areas next to Eastern and Central Thailand in the middle of the dry season $[32,34]$. The regional Gulf wind (local name: Tapao wind) blows from the middle Gulf of Thailand northward during the late dry season. Daytime UHII is relatively strong in the first quadrant (i.e., northeasterly) but relatively weak in the third (southwesterly). The weaker intensity in the third quadrant may be partly attributed to cool southerly wind from the Gulf or to warm air from the city core traveling northward to the rural area by southerly wind. The former lowers urban temperature while the latter raises rural temperature, each of which decreases UHII. These hypotheses are nonetheless subject to further investigation, which is not in the scope of this study. Nighttime UHII tends to be strong and more uniform throughout all direction in comparison with its daytime counterpart with the third (southwesterly) and fourth quadrants (northwesterly) being the most intense.

\section{Statistical relationship}

It is generally useful to formulate a statistical relationship of UHII and its associated factors, which can help to identify a set of variables influencing the urban heat land. Multiple linear regression (MLR) has been applied in urban heat island studies $[28,35]$. It was adopted here due to its simplicity and acceptable explanatory power for total variance (as shown later). In this study, the seven daily meteorological variables discussed earlier (Table 1a) were considered. Moreover, day-to-day UHII persistence (PER) was included to represent the possible influence of the past condition on the present condition (i.e., providing the background state), which can then increase the UHII predictability of the MLR. UHII persistence is set as the value of UHII on the previous day, which was found to be well correlated with UHII of the present day $(0.8$ for daytime and 0.7 for nighttime). Urban wind direction (WD) (used in the polar plots) was also included as a factor variable (whose value is 0 or 1 ). Here, the four major wind sectors or quadrants were considered, which are NE (northeasterly), SE (southeasterly), SW (southwesterly), and NW (northwesterly). Hence, a total of nine were used as the initial input or explanatory variables for the MLR below:

$$
\mathrm{UHII}=\sum_{i=1}^{n} a_{i} X_{i}+b,
$$

where $a_{i}$ and $b$ are the coefficient of the explanatory variable $\left(X_{i}\right)$ and the intercept, respectively. In the MLR modeling, certain initial variables with strong correlation with others were excluded to avoid colinearity problem. Backward stepwise elimination was applied to variable selection to reach a parsimonious set of the final variables in the regression. The adequacy of each regression model was also checked using diagnostic plots (for linearity, normality, constant error, and influential outliers), and found to be acceptable. The total variance in the original daytime UHII data was captured by as high as $82 \%$ while that of nighttime UHII is explained by $66 \%$ (Table 1b). Most of the meteorological variables in the final models have a negative coefficient, consistent with the correlation results in Table 1a. As for wind direction, only southwesterly wind is finally maintained. Its coefficient is negative $\left(-0.23^{\circ} \mathrm{C}^{-1}\right)$ 

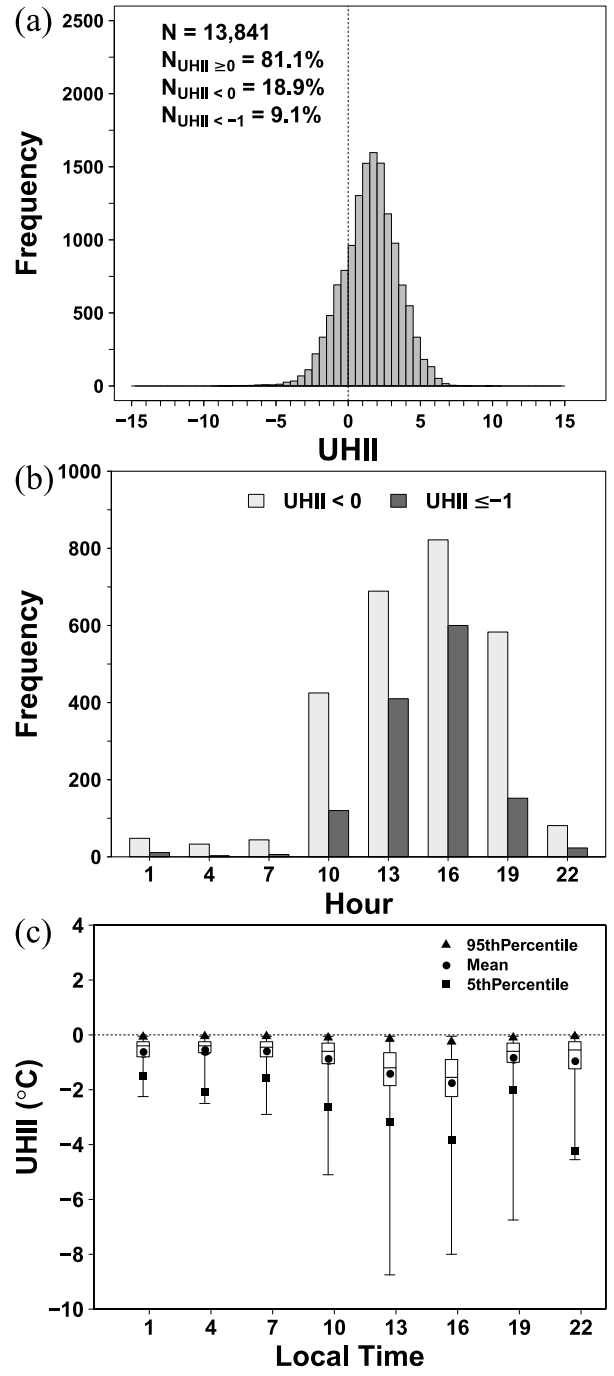

Fig. 6 (a) Histogram of negative UHII, (b) diurnal variation of negative UHII frequency, and (c) diurnal cycle of negative UHII (dry season in 2006-2015).

for the daytime model but positive $\left(0.32^{\circ} \mathrm{C}^{-1}\right)$ in the nighttime model, which is in agreement with the polar plot results where UHII appears to be suppressed and amplified in the third quadrant, respectively. Persistence is also shown to be another important variable in the regression models.

\section{Cool island condition}

It has been shown previously (Fig. 2c and Fig. 3a) that the cool island ( $\mathrm{UHII}<0^{\circ} \mathrm{C}$ ) occurs in Bangkok. Here, the cool island in the dry season was investigated, complementary to the dry-season urban heat island discussed so far. Two conditions of the cool island were considered: all-inclusive (UHII $<0{ }^{\circ} \mathrm{C}$ ) and intense $\left(<-1{ }^{\circ} \mathrm{C}\right)$. It was found that about $19 \%$ and $9 \%$ of the total three-hourly records are registered as the two cases, respectively (Fig. 6a). The majority of occurrences $(>90 \%)$ were found during the day (10-19 LT, with the peak frequency seen at $16 \mathrm{LT}$ ) for both cases (Fig. 6b). The shape of cool island intensity distribution at each hour (Fig. 6c) tends to be skewed (i.e., long-tailed) unlike that of UHII (Fig. 3a) which appears to be less skewed or more of a normal distribution. In the afternoon (13-16 LT), the cool island is more apparent, with its mean and maximal intensity being greater than $1^{\circ} \mathrm{C}$ and $8{ }^{\circ} \mathrm{C}$ (in magnitude), respectively. What causes or influences such daytime cool island? To answer this, the seven variables listed in Table 1a were re-visited. Our hypothesis is that the cool island in fact does not occur as normally expected events, and the shift to negative UHII is more induced by the intense shift of urban-rural contrast (as opposed to urban-alone variables). Accordingly, the average values of $R_{u}, \Delta R_{u-r}, C_{u}, \Delta C_{u-r}, R_{u}$, $\Delta \mathrm{RH}_{\mathrm{u}-\mathrm{r}}$, and $\mathrm{WS}_{\mathrm{u}}$ were assessed for the following three UHII cases (positive or $\geqslant 0$, negative or $<0$, and negatively large or $<-1$ ) (Fig. 7). It is apparent that all of the urban and urban-rural variables change in the same direction (from low to high values) with UHII case, which is in agreement with the correlation results. Thus, it is possible to state that the cool island is induced by the increased intensity of one or more of these variables.

\section{CONCLUSION}

The key findings from the current study are as follows:

(a) The urban heat island is intensified in the dry season, especially in Dec-Jan. UHII is relatively large at night due to the faster cooling rate during the early evening at the rural site where surface thermal admittance is lower than at the urban site.

(b) UHII is slightly larger during the weekdays than the weekend, suggesting certain influence of anthropogenic heat and land cover as the major factor influencing UHII. Thus, attention should be paid to land cover in the mitigation of urban heat island.

(c) UHII is negatively correlated with urban rain, urban-rural rain, and urban wind speed. At daytime, negative correlation with both urban cloud and urban-rural cloud is potentially caused by more shortwave radiation reflected by clouds. At night, positive correlation with urban-rural cloud was observed due possibly 

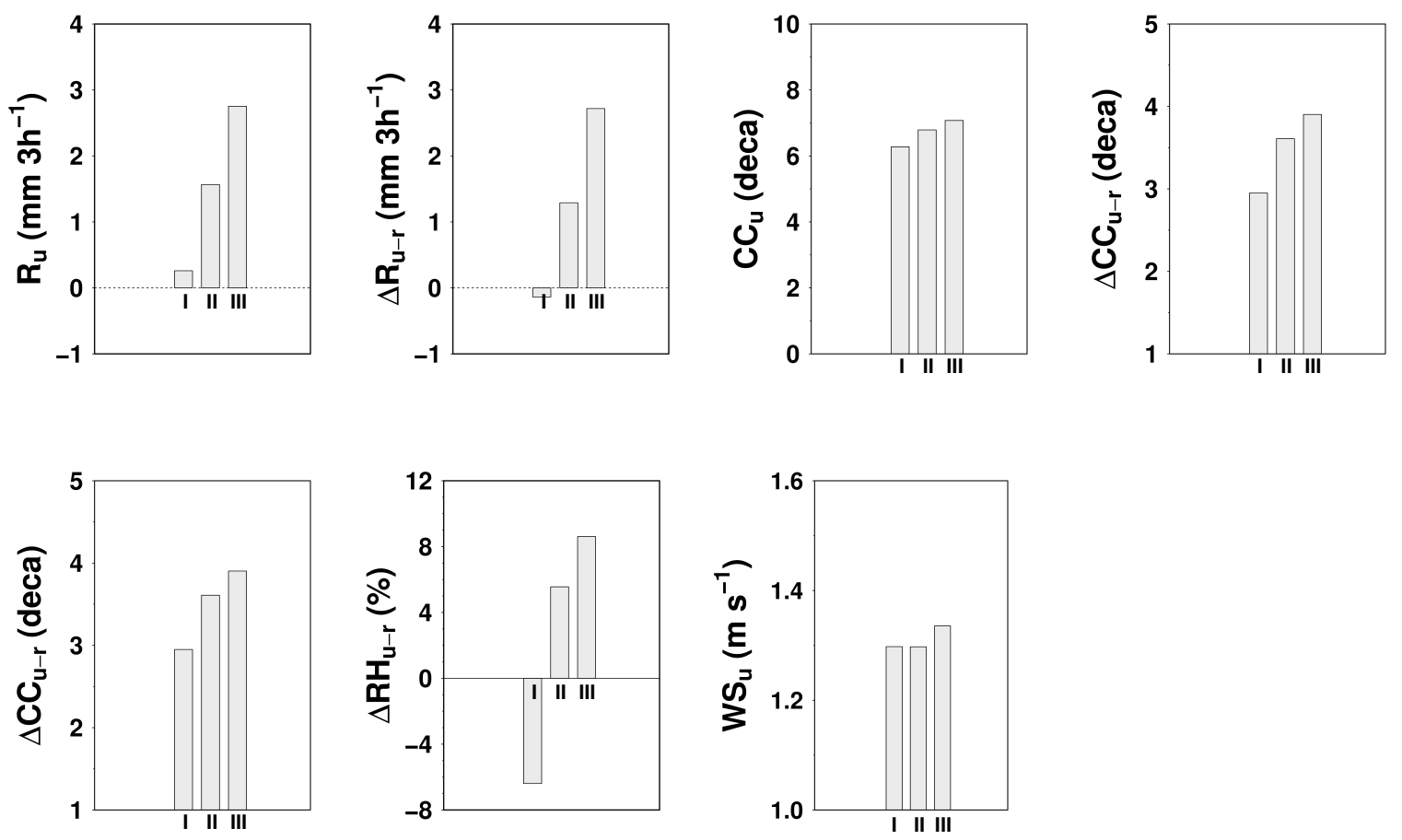

Fig. 7 Differences in urban-rural cloud cover, rain, and relative humidity by UHII case. The results are based on the three-hourly data over 10-19 LT, dry season in 2006-2015.

to longwave radiation trapped by clouds and radiated back downward. Both urban relative humidity and urban-rural relative humidity are negatively correlated with UHII.

(d) The regression models of daytime and nighttime UHII acceptably explain the variability of the original data and thus have the potential utilization in the daily forecasting of weatherrelated energy or electricity demand.

(e) The cool island phenomenon is generally induced by certain favorable urban-rural contrast in rain, cloud cover, and relative humidity.

Other aspects related to the urban heat island in Bangkok are encouraged for future studies e.g., application of numerical modeling, synoptic atmospheric pattern, and land cover change with spatial assessment. Air pollutants (especially, particulate matter) can also influence the urban heat island because they affect solar radiation and visibility [36], then modulate air temperature. Lastly, given that Thailand has also experienced extremely high temperatures [37], the development of urban heat island under such hot conditions is of additional interest.
Acknowledgements: The authors sincerely thank the Thai Meteorological Department for the observational data. This study was financially supported mainly by the Joint Graduate School of Energy and Environment and the Postgraduate Education and Research Development Office, and partly by the National Research Council of Thailand and the Asahi Glass Foundation.

\section{REFERENCES}

1. Oke TR (1987) Boundary Layer Climates, 2nd edn, Routledge Press, London, UK.

2. Grimmond CSB (1992) The suburban energy balance: methodological considerations and results for a mid-latitude west coast city under winter and spring conditions. Int J Climatol 12, 481-497.

3. Roth M (2013) Urban heat islands. In: Fernando HJS (ed) Handbook of Environmental Fluid Dynamics, CRC, pp 143-159.

4. Schwarz N, Schlink U, Franck U, Großmann K (2012) Relationship of land surface and air temperatures and its implications for quantifying urban heat island indicators - An application for the city of Leipzig (Germany). Ecol Indic 18, 693-704.

5. Srivanit M, Hokao K, Phonekeo V (2012) Assessing the impact of urbanization on urban thermal envi- 
ronment: A case study of Bangkok Metropolitan. Int J Appl Sci Technol 9, 83-100.

6. Stewart ID, Oke TR (2012) Local climate zones for urban temperature studies. Bull Am Meteorol Soc 12, 1879-1900.

7. Li D, Bou-Zeid E (2013) Synergistic interactions between urban heat islands and heat waves: The impact in cities is larger than the sum of its parts. J Appl Meteorol Climatol 52, 2051-2064.

8. McMichael AJ, Wilkinson P, Kovats RS, Pattenden S, Hajat S, Armstrong B, Vajanapoom N, Niciu EM, et al (2008) International study of temperature, heat and urban mortality: The ISOTHURM project. Int $J$ Epidemiol 37, 1121-1131.

9. Oke TR (1973) City size and the urban heat island. Atmos Environ 7, 769-779.

10. Liu W, Ji C, Zhong J, Jiang X, Zheng Z (2007) Temporal characteristics of the Beijing urban heat island. Theor Appl Climatol 87, 213-221.

11. Roth M (2007) Review of urban climate research in (sub)tropical regions. Int J Climatol 27, 1859-1873.

12. Stewart ID (2011) A systematic review and scientific critique of methodology in modern urban heat island literature. Int J Climatol 31, 200-217.

13. Santamouris M (2015) Analyzing the heat island magnitude and characteristics in one hundred Asian and Australian cities and regions. Sci Total Environ 512-513, 582-598.

14. BMA (2018) Bangkok at present (section: history and urbanization). Bangkok Metropolitan Administration, Thailand. Available at: 203.155.220.230/m. info/nowbma. [in Thai]

15. Boonjawat J, Niitsu K, Kubo S (2000) Urban heat island: thermal pollution and climate change in Bangkok. J Heal Sci 9, 49-55.

16. Jongtanom Y, Kositanont C, Baulert S (2011) Temporal variations of urban heat island intensity in three major cities, Thailand. Mod Appl Sci 5, 105-110.

17. Pakarnseree R, Chunkao K, Bualert S (2018) Physical characteristics of Bangkok and its urban heat island phenomenon. Build Environ 143, 561-569.

18. Ongsomwang S, Dasananda S, Prasomsup W (2018) Spatio-temporal urban heat island phenomena assessment using Landsat imagery: a case study of Bangkok Metropolitan and its vicinity, Thailand. Environ Nat Resource J 16, 29-44.

19. Chow WTL, Roth M (2006) Temporal dynamics of the urban heat island of Singapore. Int J Climatol 26, 2243-2260.

20. Camilloni I, Barrucand M (2012) Temporal variability of the Buenos Aires, Argentina, urban heat island. Theor Appl Climatol 107, 47-58.

21. Mohsin T, Gough WA (2012) Characterization and estimation of urban heat island at Toronto: Impact of the choice of rural sites. Theor Appl Climatol 108, 105-117.
22. Torsri K, Octaviani M, Manomaiphiboon K, Towprayoon, S (2012) Regional mean and variability characteristics of temperature and precipitation over Thailand in 1961-2000 by a regional climate model and their evaluation. Theor Appl Climatol 113, 289-304.

23. TMD (2017) Climate of Thailand, Thai Meteorological Department, Thailand. Available at: www.tmd. go.th/en/archive/thailand_climate.pdf.

24. Yang X, Hou Y, Chen B (2011) Observed surface warming induced by urbanization in east China. $J$ Geophys Res 116, ID D14113.

25. Limjirakan S, Limsakul A (2012) Observed trends in surface air temperatures and their extremes in Thailand from 1970 to 2009. J Meteor Soc Japan 90, 647-662.

26. Jin MS, Mullens T (2014) A study of the relations between soil moisture, soil temperatures, and surface temperatures using ARM observations and offline CLM4 simulations. Climate 2, 279-295.

27. Kim YH, Baik JJ (2002) Maximum urban heat island intensity in Seoul. $J$ Appl Meteorol 41, 651-659.

28. Memon RA, Leung DYC, Liu CH (2009) An investigation of urban heat island intensity (UHI) as an indicator of urban heating. Atmos Res 94, 491-500.

29. Taha H (1997) Urban climates and heat islands: albedo, evapotranspiration, and anthropogenic heat. Energy Build 25, 99-103.

30. He BJ (2018) Potentials of meteorological characteristics and synoptic conditions to mitigate urban heat island effects. Urban Clim 24, 26-33.

31. Liu W, You H, Dou J (2009) Urban-rural humidity and temperature differences in the Beijing area. Theor Appl Climatol 96, 201-207.

32. Paton C, Manomaiphiboon K (2013) A metropolitan wind resource assessment for Bangkok, Thailand part 1: wind resource mapping. J Sustainable Energy Environ 4, 69-76.

33. Carslaw DC, Ropkins K (2012) Openair - an R package for air quality data analysis. Environ Model Softw 27-28, 52-61.

34. Phan TT, Manomaiphiboon K (2012) Observed and simulated sea breeze characteristics over Rayong coastal area, Thailand. Meteorol Atmos Phys 116, 98-111.

35. Hoffmann P, Krueger O, Schlünzen KH (2012) A statistical model for the urban heat island and its application to a climate change scenario. Int J Climatol 32, 1238-1248.

36. Aman N, Manomaiphiboon K, Pengchai P, Suwanathada P, Srichawanae J, Assareh N (2019) Long-term observed visibility in Eastern Thailand: Temporal variation, association with air pollutants and meteorological factors, and trends. Atmosphere 10, ID 122.

37. Christidis N, Manomaiphiboon K, Ciavarella A, Stott PA (2018) The hot and dry April of 2016 in Thailand. Bul Amer Met Soc 99, S128-S132. 